\title{
Diet, heredity and heart disease
}

\section{By T. D. V. Lawrie and Jane L. H. C. Third, University Department of Medical Cardiology, Royal Infirmary, Glasgow $G_{4} \circ S F$}

Heart disease is now a major cause of death in the affluent, highly industrialized countries of the world. Its main form coronary heart disease (CHD) is the commonest cause of death in young and middle-aged men in the UK, showing a steady increase from 1950-1976. Coronary heart disease results from atherosclerosis of the coronary arteries; this is a lesion of the inner layer of the artery being composed of lipid, complex carbohydrate, blood products and fibrous tissue. The clinical presentations of CHD are angina pectoris, myocardial infarction, heart failure or sudden death.

The cause of CHD is still imperfectly understood in spite of a great deal of research, experimental, clinical, biochemical and epidemiological, over the past $3^{\circ}$ years. The concensus of opinion now is that there is no single cause of CHD, rather it is multifactorial in origin. This concept is largely based on epidemiological studies which have identified certain risk factors (Epstein, Ostrander, Johnson, Payne, Hayner, Keller \& Francis, 1965; Truett, Cornfield \& Kannel, 1967; Kleinbaum, Kupper, Cassel \& Tyroler, 1971); i.e. conditions which may be found in apparently healthy individuals but which carry with them an increased risk of developing CHD with the passage of time. The risk factors which have so far been suggested included hypertension, hyperlipidaemia (including diet), heavy cigarette smoking, mental stress, physical inactivity, diabetes and gout. There may be other risk factors, not at present recognized. Some of these risk factors are genetically determined, others are environmental in origin. In general terms CHD might be regarded as developing from an interplay of genetic and environmental factors but there is still debate as to their relative importance. The two major risk factors which may have a genetic component are hypertension and hyperlipidaemia. For the purpose of this dissertation it has been decided to concentrate on hyperlipidaemia and its relationship to diet on the one hand and CHD on the other.

Hyperlipidaemia may be defined as a raised level of cholesterol or triglyceride in the plasma, or both. It is well known that plasma cholesterol levels in individuals can be raised by feeding diets rich in saturated fats and that plasma cholesterol levels can be lowered by feeding diets low in saturated fats; in general the cholesterol content of the diet does not appear to be important. Similarly, plasma triglycerides can be raised by feeding excess of carbohydrates or energy to certain patients. Numerous epidemiological studies would suggest that the diet in a community has a positive relationship with plasma lipid levels and that the 
saturated fat intake is directly correlated with plasma cholesterol levels (BronteStewart, Keys \& Brock, 1955; Keys, 1970). In summary, there is circumstantial evidence that the fat content of the diet, qualitatively and quantitatively, is related directly to plasma cholesterol levels, but the relationship between diet and plasma triglyceride levels in the community is less clear.

Plasma cholesterol and triglycerides do not circulate free in the blood but are transported in combination with specific carrier proteins, the apoproteins, to form the lipoproteins.

The major plasma lipoproteins are chylomicrons, very low density lipoprotein (VLDL), low density lipoprotein (LDL) and high density lipoprotein (HDL). In certain conditions one or more of the major lipoproteins may be found in excess, resulting in several different types of hyperlipoproteinaemia. These have been classified into five major types by Fredrickson, Levy \& Lees (1967). Type II HLP has been further subdivided into types IIa and IIb (Beaumont, Carlson, Cooper, Fejfar, Frederickson \& Strasser, 1970). Type IIa HLP is characterized by elevation of LDL, the major cholesterol-carrying LP in the plasma. Type IIb is characterized by elevations of both plasma total triglyceride (carried on VLDL) and plasma total cholesterol. Types II and IV comprise greater than $90 \%$ of all lipid abnormalities and these are considered to be the important types associated with CHD. Type III is also associated with CHD but it is a rare abnormality and will not be discussed here.

In some individuals, ingestion of a high saturated fat containing diet may be directly responsible for the development of type IIa HLP. In other individuals excessive energy, or carbohydrate, or both in the diet may result in the appearance of type IV HLP. Diets rich in saturated fats and carbohydrate energy may result in the type IIb HLP (Frederickson \& Levy, 1972).

Several prospective epidemiological studies have demonstrated a close association between plasma cholesterol levels and the risk of CHD (Kannel, Dauber, Friedman, Glennon \& McNamara, 1964; Keys, r 970; Carlson \& Bottiger, 1972). A similar relationship has also been demonstrated for plasma triglyceride concentrations (Carlson \& Bottiger (1972); Salel, Riggs, Mason, Amsterdam \& Zelis, 1974; Albrink, Meigs \& Man, 1961).

The possible relationship between hyperlipidaemia or more specifically hyperlipoproteinaemia and CHD was investigated by us using the technique of selective coronary angiography. A study comparing lipoprotein patterns with the coronary angiographic findings in 133 male patients who presented with symptoms suggestive of coronary heart disease was carried out (Murray, Tweddel, Third, Hutton, Hillis, Lorimer \& Lawrie, I975). Significant coronary artery disease (CAD) was considered to be present when the lumen of any of the three major coronary arteries was occluded by at least $50 \%$. Severity of CHD was classified according to normal, single, double or triple vessel involvement. $55 \%$ of those patients with angiographically proven CHD had HLP compared with $11 \%$ of patients with normal coronary angiograms. The percentage prevalence of HLP increased with increasing degree of vessel involvement, namely $11 \%, 37 \%, 57 \%$ and $65 \%$ for 


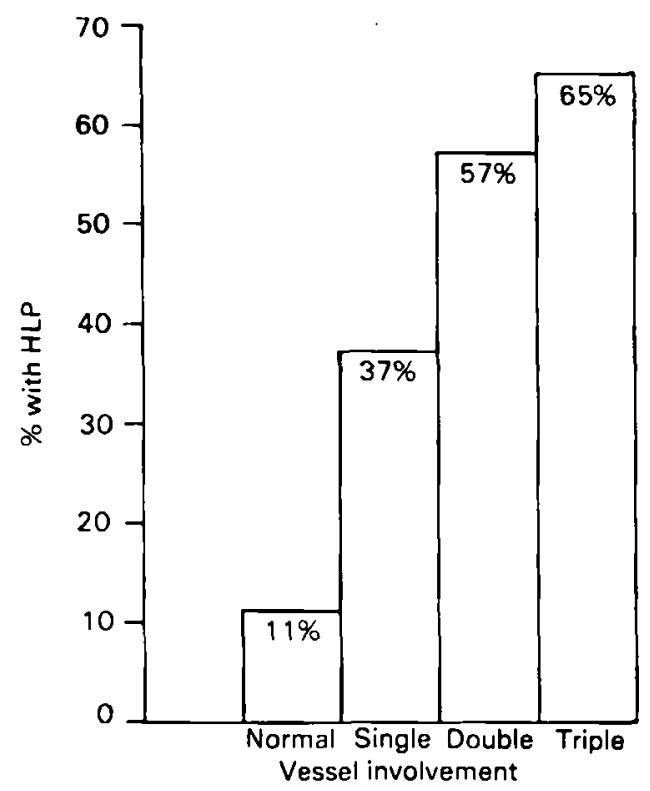

Fig. I. Correlation of percentage prevalence of hyperlipoproteinaemia (HLP) with results of coronary arteriography in 133 male patients. (Murray et al. 1975)

normal, single, double and triple vessel disease respectively (Fig. 1). HLP was also encountered more frequently in younger patients (age less than the mean for the group i.e. 47 years). The mean total plasma cholesterol concentration increased with increasing severity of $\mathrm{CAD}$ and was significantly higher than that for the group with normal coronary vessels. Supporting the association of hypertriglyceridaemia with $\mathrm{CHD}$, mean total plasma triglyceride concentrations also increased with increasing severity of $\mathrm{CAD}$ but here, the mean triglyceride concentration was only significantly higher than that of the normal group, in affected groups with double and triple vessel disease. The mean total triglyceride concentration in the younger group was significantly higher than in the older group. Lipoprotein quantification in $5^{I}$ patients in the study, also showed a significant increase in LDL cholesterol concentration in all three groups with CAD, compared with normal vessels. Several other studies (Heinle, Levy, Frederickson \& Gorling, 1969; Barboriak, Rimm, Anderson, Tristani, Walker \& Flemma, 1974) relating HLP and coronary angiographically proven CHD support the above results, and a frequency of HLP as high as $74 \%$ has been reported by Falsetti, Schnatz, Green \& Bunnell (1970). These studies strongly suggest that the severity of coronary atherosclerosis is directly related to the severity of HLP. In view of the relationship of dietary factors to plasma cholesterol and plasma triglyceride and the association of HLP with CAD, it is tempting to conclude that dietary factors, via their effects on plasma lipid levels, play an important part in the development of coronary atherosclerosis which is the basis for developing the clinical manifestations of CHD. 
Hereditary factors are also known to play a role in the development of CHD. Clear cut evidence of an inherited predisposition to CAD is seen in those cases of severe familial type II hyperlipoproteinaemia. Detailed family studies of patients with severe familial type II HLP demonstrate a Mendelian autosomal dominant mode of inheritance due to a single mutant gene (Khachadurian, I964; Nevin \& Slack, 1968; Frederickson et al. 1972).

The frequency of this condition in the American population has been estimated to be between 0.5 and $0.1 \%$ (Motulsky, 1976). The majority of patients are, of course, heterozygotes for the condition with a single dose of the abnormal gene, with at least one parent with the disorder. In addition, on average, $50 \%$ of the children of an affected parent will have the condition. Clinically the heterozygote is characterized by high plasma total cholesterol greater than $300 \mathrm{mg} / 100 \mathrm{ml}$ and the presence of tendon xanthomata, which develop in the twenties or later. Xanthelasma and corneal arcus are frequently present in addition, although they may be found in those who do not have HLP. The condition is associated with a very high risk of death from premature CHD (IHD), as shown by numerous family studies (Frederickson et al. 1972). Slack (1969) has estimated that for men with type II HLP the chance of a first attack of IHD was $5.4 \%$ by age $30,51.4 \%$ by age 50 and $85.4 \%$ by age 60 while for women the risks were $0,12.2 \%$ and $57.5 \%$ respectively. The homozygotes for familial type II HLP are extremely rare accounting for an estimated one case per million of the population consistent with the expected frequency of mating between heterozygotes (Motulsky, 1976). The homozygotes have extremely high plasma total cholesterol levels, often greatly in excess of $600 \mathrm{mg} / 100 \mathrm{ml}$ with very extensive xanthomatous deposits, sometimes present from birth, and death from CHD is usual in childhood or late adolescence (Frederickson et al. 1972). Both parents of affected individuals must, of course, be heterozygotes.

Relatively recent studies by Kwiterovich et al. (1973) have suggested that the diagnosis of autosomal dominant familial type II HLP can be made at birth using cord blood sampling of neonates with one parent known to have the disorder. This has important implications in terms of early therapeutic intervention at a time when the hope of successful prevention or at least retardation of the development of CHD is greatest. We have evaluated the value of cord blood sampling as a screening procedure at birth in the general population for the familial type II HLP (Third, Ballantyne, Murray \& Lawrie, unpublished results). Five hundred consecutive neonate cord blood samples were obtained and full lipoprotein analysis was performed. Of 25 neonates considered to have HLP at birth 15 were available for re-examination I year later. No baby in this group was found to have type II HLP on re-examination and mean LDL and total cholesterol levels at I year was not statistically different between the abnormal and control group babies, nor for control parents and parents of abnormal babies group (Table 1 ). We have concluded that neonatal screening of the general population is of no value in the diagnosis of type II HLP at birth. Darmady, Fosbrooke \& Lloyd (1972), measuring total cholesterol concentrations in cord blood, concluded that serum cholesterol 
estimations in cord blood cannot be used as a screening test for the diagnosis of familial hypercholesterolaemia. In another large study, using very restrictive criteria, 8 of 1800 unselected neonates were identified as having the monogenic autosomal dominant form of type II HLP (Tsang, Fallat \& Glueck, 1974). The diagnosis was confirmed by an elevated cord blood LDL cholesterol, demonstration of three generation transmission of the disorder, and persistence of high LDL cholesterol levels at age I year. These authors suggest, therefore, a minimal estimate of the heterozygotes frequency to be $0.44 \%$.

Table I. Glasgow Royal Infirmary cord blood study on low density lipoprotein and total cholesterol concentrations in 500 babies and their parents

(Results are expressed as mean \pm ISD)

\begin{tabular}{|c|c|c|c|c|c|c|c|c|}
\hline \multicolumn{3}{|c|}{ Cord } & \multicolumn{3}{|c|}{ Follow-upt } & \multicolumn{3}{|c|}{ Parents } \\
\hline & $\mathrm{T}$ & LDL & No. & Total & & No. & T & LD \\
\hline ( & $\begin{array}{r}133 \pm \\
74 \pm\end{array}$ & $\begin{array}{l}87 \pm 11 \\
36 \pm 10\end{array}$ & $\begin{array}{l}15 \\
18\end{array}$ & $\begin{array}{l}165 \pm 35 \\
173 \pm 33\end{array}$ & $\begin{array}{l}108 \pm 45 \\
117 \pm 30\end{array}$ & $\begin{array}{l}26 \\
38\end{array}$ & $\begin{array}{l}208 \pm 45 \\
209 \pm 3^{2}\end{array}$ & $13^{8} \pm 3^{\circ}$ \\
\hline
\end{tabular}

-Abnormal group: babies with cord blood LDL cholesterol >Mean+2SD for total group of neonates $(500)$.

†Control group: babies with cord blood LDL cholesterol within ISD of the mean for total group of babies $(500)$.

tFollow up at approximately one year of babies and their parents.

The majority of individuals considered to have type II HLP suffer from milder elevations of plasma total cholesterol and LDL concentrations, and the presence of xanthomata is much less frequent than in autosomal dominantly inherited type II HLP. The mode of inheritance was examined in 158 first degree relatives of 55 index patients with peripheral vascular disease and mild type II HLP (Ballantyne \& Lawrie, 1975). Only 43 first degree relatives were found to have type II HLP. There was no evidence of a $I: 1$ relationship between affected and non-affected individuals and the distribution of plasma total cholesterol and LDL cholesterol concentrations was of a unimodal type (Figs 2 and 3 ). This supports the view that the milder forms at least of type II HLP have a polygenic rather than a monogenic mode of inheritance as is thought to be the case for the classical severe familial type II HLP. It is this commoner type of inherited hypercholesterolaemia which makes a greater contribution to CHD rates: especially when rendered more susceptible by the consumption of the Western high saturated fat containing diets.

Genetic studies on patients with type IV HLP are fewer than in type II HLP, but an autosomal dominant mode of inheritance with delayed expression has been demonstrated in a number of studies (Fredrickson et al. 1972); Goldstein, Schrott, Hazzard, Bierman \& Motulsky, 1973). Type IV HLP is very rarely found in those families before age 20 years. Environmental influences are probably equally important as genetic factors in this type of HLP. Frequent associations with type IV HLP are obesity and excessive alcohol indulgence. 


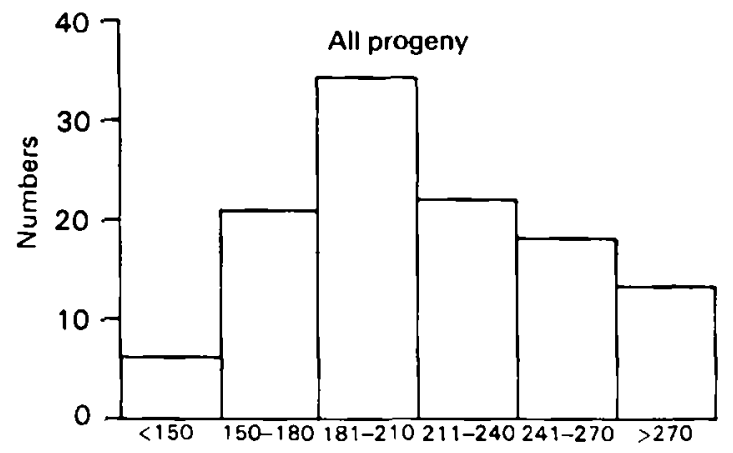

Plasma total cholesterol concentration (mg/100 $\mathrm{ml}$ )

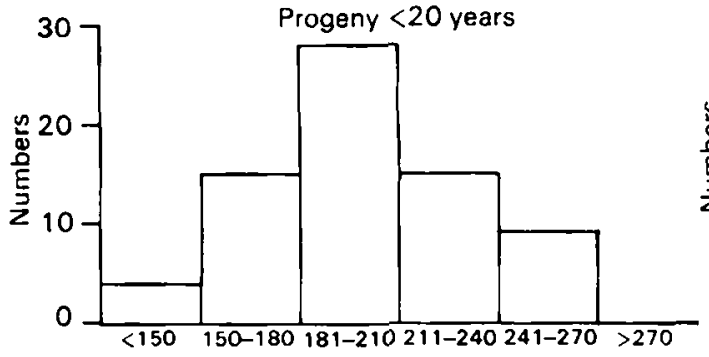

Plasma total cholesterol concentration $(\mathrm{mg} / 100 \mathrm{ml}$ )

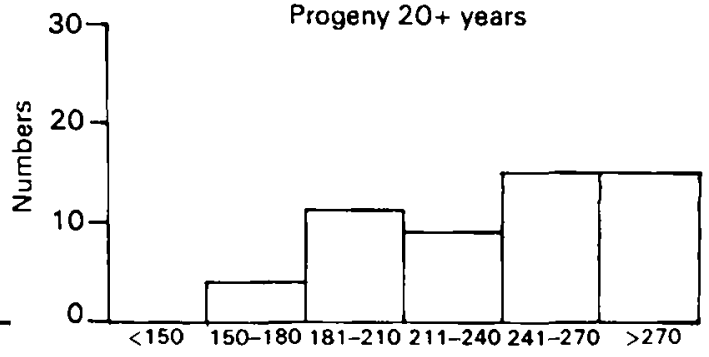

Plasma total cholesterol concentration $(\mathrm{mg} / 100 \mathrm{ml}$ )

Fig. 2. Distribution of plasma total cholesterol concentration in the progeny, divided into those less than 20 years to correct for age-related increase in cholesterol concentrations with age. (Ballantyne \& Lawrie, 1975).

Administration of the contraceptive pill is responsible for the development of type IV HLP in some women. High carbohydrate content diets are responsible for the disorder in others. Correction of obesity and stopping the taking of alcohol, the contraceptive pill or excessive dietary carbohydrate very frequently corrects the abnormality without any further treatment. The latter supports a considerable dietary influence in the development of type IV HLP.

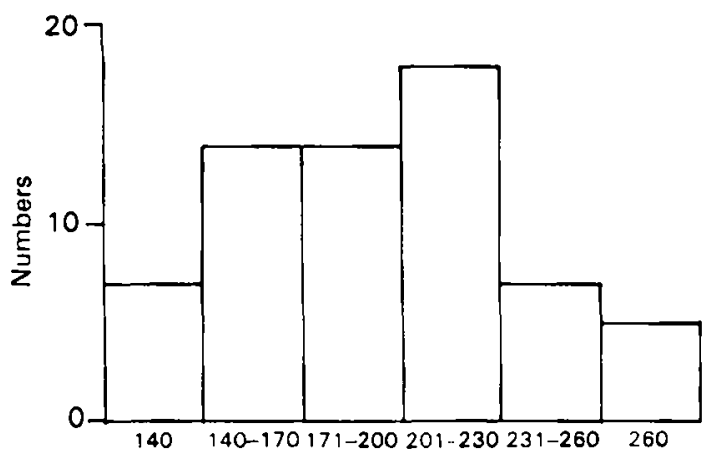

Plasma LDL cholesterol concentration $(\mathrm{mg} / 100 \mathrm{ml})$

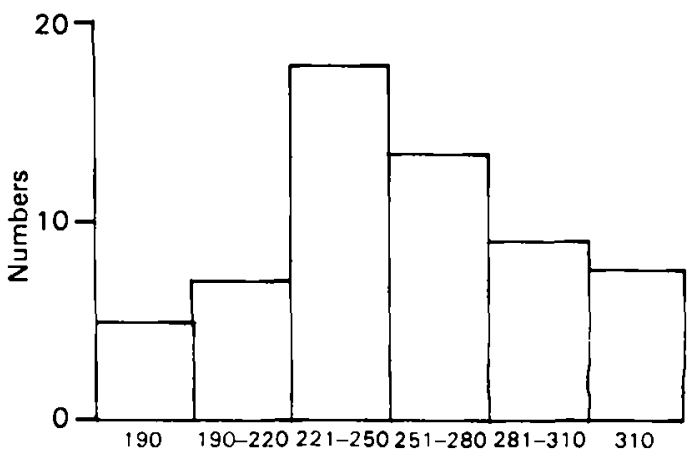

Plasma total cholesterol concentration $(\mathrm{mg} / 100 \mathrm{mi})$

Fig. 3. Distribution of plasma total cholesterol and low density lipoprotein (LDL) cholesterol concentrations in the siblings. (Ballantyne \& Lawrie, 1975). 
At the present time it is not possible to state accurately the prevalence of the familial form of type IV HLP, and more extensive family studies of patients with type IV HLP require to be done. The majority of patients seen at our lipoprotein clinic who have type IV HLP appear to have the form of the disorder most commonly due to excess of energy, in particular carbohydrate, in the diet. Alcohol may be an important factor, often responsible in those patients with very high triglyceride concentrations.

One other form of inherited lipid disorder, described as Familial combined hyperlipidaemia, has been reported by Goldstein et al. (1973). This form may express itself either as an isolated hypercholesterolaemia, or as hypertriglyceridaemia or both in affected individuals of such families. The condition is seldom apparent before age 20 years. The exact mode of transmission is not yet clear. Goldstein's results are consistent with an autosomal dominant mode of inheritance of a single gene, although its expression is obscure. Another report on this familial combined hyperlipoproteinaemic state suggests that two different genes may be operating sometimes independently, at other times together (Rose, Kranz, Weinstock, Juliano \& Haft, 1973). The disorder has been estimated to have a prevalence of around $1.5 \%$ in a study of a middle-aged male Seattle population and is also associated with premature CHD (Motulsky, 1976).

There is no doubt that hypercholesterolaemia and hypertriglyceridaemia, are associated with the risk of development of premature CHD. These hyperlipidaemic states arise from a combination of both genetic and dietary factors. Genetic factors have greatest import in the severe familial autosomal dominant type II HLP, as is demonstrated by almost invariable failure to normalize the lipid levels even on a strict low saturated fat, low cholesterol diet, and often despite drug therapy in addition. At the other end of the spectrum are these type IV individuals whose abnormality arises predominantly from dietary excess of energy carbohydrates or both, and in whom complete normalization of triglyceride levels may frequently be achieved by appropriate dietary correction.

Since there is good circumstantial evidence, but no absolute proof, to suggest that various dietetic factors are positively correlated with plasma lipid levels, severity of coronary atherosclerosis and clinical manifestation of CHD, the question arises as to whether dietetic treatment of the community as a whole is to be recommended for CHD. The evidence suggests that once a myocardial infarction has occurred dietetic therapy aimed at lowering plasma lipid levels achieves very little and attention is now being directed at primary prevention of the clinical manifestation of CHD. A recent report of a joint working party of the Royal College of Physicians of London and the British Cardiac Society (1976) has recommended some dietetic changes for the whole country. This recommendation has not been completely accepted and we would suggest that a more selective approach be adopted. Aims at primary prevention require identification of those individuals known to be at risk of developing CHD in the future. This would involve lipid screening of relatives of patients known to have HLP or a family history of premature CHD. Thereafter classification of the lipid abnormality into 
the specific lipoprotein type followed by institution of appropriate dietary, or drug therapy or both is desirable, and at the earliest possible age, ideally at birth or shortly thereafter if treatment is to have any hope of success in reducing mortality from premature CHD.

Justification for what seems to some a drastic alteration in the lifestyle of affected individuals lies in the demonstration that such measures are accompanied by an elimination or at least reduction of the high risk of premature CHD. Results of a number of preventive trials have been encouraging but it still remains to be proven that such treatment is effective in ultimately reducing the death rate from CHD.

\section{J.L.H.C.T. is a Pfizer Research Fellow.}

\section{REFERENCES}

Albrink, N. J., Meigs, J. N. \& Man, E. B. (196I). Am. f. Med. 31, 4.

Ballantyne, D. \& Lawrie, T. D. V. (1975). Scott. med. J. 20, 1.

Barboriak, J. J., Rimm, A. A., Anderson, A. J., Tristani, F. E., Walker, J. A. \& Flemma, R. J. (1974). Am. Heart F. 87, 716 .

Beaumont, J. L., Carlson, L. A., Cooper, G. R., Fejfar, Z., Fredrickson, D. S. \& Strasser, T. (1970). Bull. Wld Hlth Org. 43, 891.

British Cardiac Society (1976). YlR. Coll. Physicians 10, 3.

Bronte-Stewart, B., Keys, A. \& Brock, J. F. (1955). Lancet ii, I I03.

Carlson, L. A. \& Bottiger, L. E. (1972). Lancet ii, 865.

Darmady, J. M., Fosbrooke, A. S. \& Lloyd, J. K. (1972). Br. med. F. xx, 685.

Epstein, F. H., Ostrander, J. L. D., Johnson, B. C., Payne, M. W., Hayner, N. S., Keller, J. B. \& Francis Jr, T. (1965). Ann. intern. Med. 62, 1170.

Falsetti, H. L., Schnatz, J. D., Greene, D. G. \& Bunnell, I. L. (1970). Chest 58, in I.

Fredrickson, A. S. \& Levy, R. I. (1972). In The Metabolic Basis of Inherited Diseases. 3rd edn pp. 564-579, 592-604. [J. B. Stanbury, J. B. Wyngaarden \& D. S. Fredrickson, editors]. New York: McGraw-Hill.

Fredrickson, D. S., Levy, R. I. \& Lees, R. S. (1967). New Engl. F. Med. xx, 276.

Goldstein, J. L., Schrott, H. G., Hazzard, W. R., Bierman, E. L. \& Motulsky, A. G. (1973). f. Clin. Invest. 52, 1544 .

Heinle, R. A., Levy, R. I., Fredrickson, D. S. \& Gorlin, R. (I969). Am. F. Cardiol. 24, 178.

Kannel, W. B., Dauber, T. R., Friedman, G. D., Glennon, W. E. \& McNamara, P. M. (1964). Ann. intern. Med. 6r, 888.

Keys, A. (1970). Circulation 41, suppl. I.

Khachadurian, A. K. (1964). Am. J. Med. 37, 402.

Kleinbaum, D. G., Kupper, L. L., Cassel, J. C. \& Tyroler, H. A. (1971). Arch. intern. Med. 128, 943.

Kwiterovich, P. O., Levy, R. I. \& Fredrickson, D. S. (1973). Lancet 118.

Motulsky, A. G. (1976). New Engl. Y. Med. 294, 832.

Murray, R. G., Tweddel, A., Third, J. L. H. C., Hutton, I., Hillis, W. S., Lorimer, A. R. \& Lawrie, T. D. V. (1975). Br. Heart f. 37, 1205.

Nevin, N. C. \& Slack, J. (1968). J. med. Genet. 5, 9.

Rose, H. G., Kranz, P., Weinstock, M., Juliano, J. \& Haft, J. I. (1973). Am. J. Med. 54, 148.

Salel, A., Riggs, K., Mason, D. T., Amsterdam, E. A. \& Zelis, R. (1974). Am. F. Med. 57, 897.

Slack, J. (1969). Lancet ii, 380 .

Truett, J., Cornfeld, J. \& Kannel, W. (1967). F. chron. Dis. 20, 51 r.

Tsang, R. C., Fallat, R. W. \& Gluech, C. J. (1974). Paediatrics 53, $45^{8}$. 